\title{
Pattern of male sex hormones in type 2 diabetic patients in Nnewi, South Eastern Nigeria.
}

\author{
${ }^{1}$ Onah C.E, ${ }^{2 ; 3}$ Meludu S.C, ${ }^{3}$ Dioka C.E, ${ }^{3}$ Onuegbu J.A, ${ }^{3}$ Amah U.K, \\ ${ }^{3}$ Olisekodiaka M.J, ${ }^{3}$ Okwara J.E, ${ }^{4}$ Onah C.F, ${ }^{2}$ Ezeugwunne I.P. \\ ${ }^{I}$ Department of Chemical Pathology, Nnamdi Azikiwe University Teaching Hospital, Nnewi. \\ ${ }^{2}$ Department of Human Biochemistry, Faculty of Basic Medical Sciences, College of Health Sciences, Nnamdi \\ Azikiwe University, Nnewi campus. \\ ${ }^{3}$ Department of Chemical Pathology, Faculty of Medicine, Nnamdi Azikiwe University, Nnewi campus. \\ ${ }^{4}$ Department of Nursing Services, Nnamdi Azikiwe University Teaching Hospital, Nnewi.
}

\begin{abstract}
Background: Type 2 diabetes mellitus has been shown to be associated with certain endocrine disorders in men. We therefore investigated the levels of male sex hormones in serum of patients with type 2 diabetes mellitus (DM2) and non-diabetic controls (NDMC) with a view to establishing the effect of diabetes mellitus on their endocrine system. Methods: One hundred and twenty five male type 2 diabetic subjects and 50 apparently healthy non-diabetic male individuals within the age of $32-70$ years were recruited into this study. Fasting plasma glucose (FPG), male sex hormones (follicle stimulating hormone (FSH), prolactin, luteinizing hormone (LH), and testosterone), and body mass index (BMI) were determined. Results: The mean value of $F P G$, FSH and prolactin were significantly higher in diabetic subjects when compared with the NDMC, but there was no significant difference in the levels of LH and BMI. The level of testosterone was significantly lower in diabetics than in NDMC. There was no significant correlation between duration of diabetes and male sex hormones (FSH, LH, Prolactin and Testosterone). Results also showed that male sex hormones, BMI, FPG, are independent of age. Conclusion: This study revealed decreased levels of testosterone with insignificantly high levels of luteinizing hormone which is suggestive of abnormal feedback mechanism in the hypothalamicpituitary-testicular axis of these diabetic men. The study also revealed a significant raised serum prolactin levels in type 2 diabetic patients without a definitive cause. We therefore, recommend further studies to elucidate the possible underlying mechanisms involved in these abnormalities so that correct strategies for treatment can be employed.
\end{abstract}

Key words: Body Mass Index, hypogonadism, Prolactin, Testosterone, Type 2 diabetes mellitus.

\section{Introduction}

Diabetic mellitus is a group of metabolic diseases in which a person has high plasma glucose, either because the body does not produce enough insulin, or because cells do not respond to the insulin that is produced. The high plasma glucose produces the classical symptoms of polyuria, polydipsia and polyphagia. ${ }^{[1]}$ Type 2 diabetes mellitus, formerly non-insulin dependent diabetes mellitus or adult onset diabetes, is a metabolic disorder that is characterized by hyperglycemia in the context of insulin resistance and relative insulin deficiency. ${ }^{[2]}$ Over $90 \%$ of people with diabetes mellitus are type 2 diabetics and it is reported to be associated with certain endocrine disorders, in particular hypogonadism in men. ${ }^{[3,4]}$

Several studies linked low testosterone level to type 2 diabetes, but they have not received much attention probably because both type 2 diabetes and low testosterone levels are associated with aging; as a high proportion of older men will have both diabetes and low testosterone levels. However, some clinical studies on men of same age have shown that the level of testosterone is lower in diabetic men as compared to non-diabetic men. ${ }^{[4-6]}$

Testosterone is the major male androgen and is produced by the leydig cells in the male testis and in smaller amounts by the adrenal glands. It is responsible for male secondary sexual characteristics and sperm production. The effects of low testosterone levels include low sex drive, changes in mood, loss of muscle and bone strength, and increase body fat. ${ }^{[7]}$ The amount of testosterone synthesized is regulated by the hypothalamic-pituitary-testicular axis. When testosterone levels are low, gonadotropin-releasing hormone $(\mathrm{GnRH})$ is released by the hypothalamus which in turn stimulates the pituitary gland to release FSH and LH. These latter two hormones stimulate the testis to synthesize testosterone ${ }^{[8]}$ This means that when the feedback mechanism is functioning properly, low testosterone level will induce secretion of high FSH and LH levels.

However, study carried out by Saudeep et al. has shown that both free and total testosterone levels are lower in men with type 2 diabetes than in non-diabetic men and their levels of pituitary hormones (FSH and LH) 
were much lower than expected. ${ }^{[9]}$ Also, Dhindsa et al showed that among diabetics with hypogonadism, LH and FSH levels were significantly lower in comparison with patients with normal free testosterone levels. ${ }^{[5]}$

Ballister et al, indicated in their work that STZ- induced diabetes causes a marked decrease in both insulin and LH levels. ${ }^{[10]}$ They are of the view that the changes in leydig cell number and function observed in STZ-diabetic rats may be as a result of low LH and insulin level. This is because Feng et al, have indicated in their work that LH mediates the proliferation of laydig cells through a mechanism that involves insulin and IGFI signaling ${ }^{[11]}$ Also insulin has shown a partial restoration of alteration in lipid metabolism in cultured leydig cells from diabetic rats. ${ }^{[12]}$ With regard to the strong relationship between lipid metabolism and androgen biosynthesis, ${ }^{[13]}$ the recovery of this metabolism leads to a concomitant effect on testosterone biosynthesis. ${ }^{[10]}$

Prolactin a polypeptide also known as pituitary hormone has the ability to promote lactation in response to the suckling stimulus of hungry young mammals. ${ }^{[14]}$ The functions of prolactin is related to reproduction, growth and development, metabolism, immune regulation, brain function and behavior. ${ }^{[15]}$ Mooradian et al, has reported a significant higher serum prolactin level in DM2 than in NDMC ${ }^{[16]}$ Studies have shown that prolactin level affect glucose metabolic regulation in both pregnant ${ }^{[17]}$ and non-pregnant individuals. ${ }^{[18]}$

The paucity of information in the levels of male sex hormones in this group of subjects in South Eastern Nigeria, particularly in Nnewi Anambra State, necessitated this investigation. This study is therefore, designed to investigate the levels of male sex hormones in serum of patients with type 2 diabetes mellitus and non-diabetic controls with a view to establishing the effect of diabetes mellitus on their endocrine system.

\section{a. Study Design and Population}

\section{Materials And Methods}

This was a cross-sectional randomized study designed to investigate the levels of male sex hormones in male DM2 patients and in NDMC. The study design received an approval from the Ethics Committee of Nnamdi Azikiwe University Teaching Hospital (NAUTH) Nnewi. The informed consents of all the participants were sorted and all the participants freely volunteered.

A total number of 175 participants were recruited for this study. The subjects were grouped into two categories comprising 125 known DM2 male subjects recruited from the Medical Out-Patient Department of NAUTH, Nnewi and 50 NDMC who are staff of NAUTH, Nnewi. The study population is known DM2 male patients within the age range (32-70 years) attending Nnamdi Azikiwe University Teaching Hospital (NAUTH), Nnewi (Eastern Nigeria) and non-diabetic male individuals within the same age range (32-60 years). Among NDMC group, those that consume alcohol or smoke cigarette regularly or have any form of chronic illness such as hypertension, renal disease, heart problems etc were disqualified. Out of 53 control individuals that were finally selected 3 were disqualified based on their fasting plasma glucose that are above $7.0 \mathrm{mmol} / \mathrm{L}$ as recommended by WHO. ${ }^{[19]}$

All male patients with DM2 were considered eligible for this project, irrespective of age, duration of diabetes, complication, and treatment except those that take alcohol or smoke cigarette regularly or those under hormonal therapy. Patients' medical history such as age, diabetes treatment and complications were obtained from their folders. Other diabetes-specific data such as duration of diabetes (DDM), and prevalence of erectile dysfunction (ED) were determined by questionnaire. Patients were grouped into three classes (Never, Occasionally and often) according to reported frequency of ED by asking the patients how often they had experienced problems in attaining and maintaining an erection. Their BMI were calculated using their measured height and weight.

\section{b. Blood sample collection and Biochemical analysis}

$5 \mathrm{mls}$ of Venous blood samples were collected from all respondents for the analysis. A part was dispensed into fluoride oxalate bottles for glucose determination using standard enzymatic spectrophotometric method. The remaining part was dispensed into a plain bottle and allowed to clot, retract and the serum stored at $-20^{\circ} \mathrm{C}$ until analysis of male sex hormones using Enzyme Linked Immunosorbent Assay (ELISA) method.

All the analysis was done by following the manufacturer's procedure strictly (TECO DIAGNOSTICS http://www.tecodiag.com for the male sex hormones and RANDOX www.randox.com for FPG analysis. The equipments used are BECKMAN COULTER (DU 720) General Purpose UV/Vis Spectrophotometer and AWARENESS TECHNOLOGY INC (Stat Fax - 2100) Microplate Reader.

\section{c. Statistical analysis}

The version 17 of Statistical Package for Social Sciences (SPSS) was used in statistical analysis. All data were expressed as the mean \pm standard deviations. Comparisons between groups were performed by using a one-way ANOVA. Association between two variables was determined using Pearson's correlation coefficient. 
Student's t-test was used when comparing two groups. Differences with $\mathrm{P}$ values $<0.05$ were considered significant.

\section{Results}

One hundred and twenty five diabetic patients were studied. Out of this number, 55 (44\%) reported frequent ED problems, 49 (39.2\%) reported occasional ED problems, and 21 (16.8\%) reported no ED. In the same vein, $64(51 \%)$ have normal weight, $48(38.4 \%)$ are overweight while $13(10.4 \%)$ are obese. The mean Age, BMI, and DDM in diabetic patients are 51.58 $\pm 8.6,25.31 \pm 2.7$, and 7.7 \pm 5.7 respectively. The frequency of ED in this study population was associated with BMI, diabetes complication, and treatment of diabetes (Table 1).

The mean FPG, FSH and Prolactin were significantly higher in diabetic subjects when compared with the control subjects. Conversely, the mean testosterone was significantly lower in diabetic subjects when compared with the control subjects. However, there was no significant difference between the mean levels of LH and BMI in diabetic subjects and in non-diabetic control subjects (Table 2).

DDM did not show any significant correlation with the Male Sex Hormones (Testosterone, FSH, LH, and Prolactin) in type 2 diabetic subjects (Table 3). The result showed that there is no significant difference in the mean levels of male sex hormones, BMI, and FPG within these age groups. This indicates that the levels of male sex hormones, BMI, and FPG are independent of age (Table 4).

The comparison of different categories of BMI: normal weight (18.5-24.9 Kg/ $\left.\mathrm{M}^{2}\right)$, overweight (25-29.9 $\mathrm{Kg} / \mathrm{M}^{2}$ ), and Obesity (30-39.9 Kg/ $\left.\mathrm{M}^{2}\right)$ with the mean levels of different hormones showed an interesting relationship. The mean level of Prolactin increased significantly from normal weight to obesity $(\mathrm{F}=11.22, \mathrm{P}=$ 0.001 ) while the mean levels of Testosterone and FSH decreased significantly from normal weight to obesity $(\mathrm{F}=6.68, \mathrm{P}=0.002)$ and $(\mathrm{F}=4.92, \mathrm{P}=0.009)$ respectively. However, there is no significant difference of mean $\mathrm{LH}$ level within the BMI categories ( $\mathrm{F}=1.99, \mathrm{P}=0.141)$ (Fig. 1).

\section{Discussion}

In this study, testosterone was significantly lower in men with DM2 than in NDMC. This work agreed with other findings of several authors. ${ }^{[4-6]}$ The actual cause or causes of this low level of testosterone in diabetes have not been fully elucidated. Though, the hypogonadal-obesity cycle described by Cohen, ${ }^{[22]}$ and Kapoor et $\mathrm{al},{ }^{[23]}$ suggests that during the hypogonadal state, there is an increase in aromatase activity leading to a greater formation of $17 \beta$-estradiol from testosterone. As a consequence, this leads to further reduction in serum and tissue concentrations of testosterone and increased deposition of abdominal fat and progressive hypogonadism.

This speculation seems to be in consonant with the result of this present work because most of the patients that are obese have lower testosterone level than the normal weight group (Fig.1). However, it has been shown that hypogonadism is not dependent on obesity. Dhindsa et al showed that $25 \%$ of non-obese men with diabetes also had hypogonadatrophic hypogonadism. ${ }^{[5]}$ According to Dandona et al, insensitivity to insulin at the hypothalamic level may cause the development of hypogonodotrophic hypogonadism because insulin is associated with an increased concentration of inflammatory proteins in the blood which directly suppress the release of gonadotrophin-releasing hormone from the hypothalamus. ${ }^{[24]}$

In this study the mean level of FSH is significantly higher in DM2 than in NDMC. However, the level of LH is raised in DM2 than in NDMC but it is not statistically significant. The reports on the levels of gonadotrophic hormones (FSH and LH) were conflicting. Natah et al, ${ }^{[25]}$ and Ali et al,${ }^{[26]}$ reported a significant higher FSH and LH levels in diabetics than in control. Ando et al, reported a normal FSH and LH levels in diabetic males, ${ }^{[27]}$ while Hussein and Al-Qatsi showed a significant reduction in serum FSH and LH of diabetic patients of both sex compared to healthy individuals. ${ }^{[28]}$ In this condition of low testosterone level, one would expect that LH level should be significantly higher than what is obtained considering its effect in testosterone production. A study conducted among diabetics, showed that in those diabetics with hypogonadism, FSH and LH levels were much lower than expected and this could be as a result of a malfunction in the pituitary gland or hypothalamus of these hypogonadal diabetic men. ${ }^{[5]}$

It has been postulated that diabetes mellitus affect not only insulin level but also causes a marked decrease in LH level. For instance, the result from Ballister et al, work indicates that STZ-induced diabetes causes a marked decrease in both insulin and LH levels. ${ }^{[10]}$ Moreso, Seethalakshmi et al, showed a diminished stimuli-induced secretion of FSH and LH in a diabetic rat. ${ }^{[29]}$ This indicates that there is a relationship between insulin/glucose and LH/FSH levels in serum, though the mechanisms by which insulin, glucose, or both control these 2 hormones are unclear. ${ }^{[10]}$ Another reason for the findings may be as a result of high oxidative stress generated in diabetic patients which could affect the normal functioning of the pituitary gland and hypothalamus.

This study showed an increased level of prolactin in diabetic subjects than in control. This is in agreement with the work done by Mooradian et al. ${ }^{[16]}$ The cause of elevated prolactin level in diabetics is still 
unclear. However, Saller and Chiodo reported that glucose administration in the rat suppresses the firing of central dopamine neurons. ${ }^{[30]}$ It is tempting to speculate that chronically elevated blood glucose in diabetics could raise serum prolactin level by suppressing dopaminergic neuronal activity, ${ }^{[16]}$ a known inhibitor of

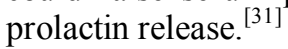

There is evidence that high levels of prolactin can cause hypothalamic pituitary dysfunction and can suppress gonadal function directly. ${ }^{[32]}$ In this regard, low levels of testosterone without commensurate increase in LH as found in this present study might be partially as a result of high levels of prolactin observed in our patients especially when we look at relationship between the BMI categories and male sex hormones (Fig.4).

\section{Conclusion}

This study revealed decreased levels of testosterone with insignificantly high levels of LH which is suggestive of abnormal feedback mechanism in the hypothalamic-pituitary-testicular axis of these diabetic men. The study also revealed a significant raised serum prolactin levels in type 2 diabetic patients without a definitive cause. We therefore, recommend further studies that will include HbAlc assay and sophisticated techniques in order to elucidate the possible underlying mechanisms involved in these abnormalities so that correct strategies for treatment can be employed.

\section{References}

[1]. Rother KI. Diabetes treatment-bridging the divide. New Eng J Med 2007; 356:1499-1501

[2]. Vinay K, Abul KA, Nelson F. Robbins Pathologic Basis of Disease, $6^{\text {th }}$ Edition Philadelphia: Elsevier Inc.; 1999. p. $913-926$.

[3]. Burtis CA, Ashwood ER, Bruns DE. Tietz Textbook of Clinical Chemistry and Molecular Diagnostics. India: Reed Elsevier; 2008. p. 854-900.

[4]. Rosen ED. Low testosterone in Type 2 Diabetes: A hidden epidemic. www.diabetesincontrol.com/index.php?option=com content\&view article\&id=2324 20/3/2012.

[5]. Dhindsa S, Prabhakar S, Sethi M, Bandyopadhyay A, Chaudhuri A, Dandona D. Frequent occurrence of hypogonadism in type 2 Diabetes. J Clinical Endocrinol Metab 2005; 90:1903

6. Obesity linked to low testosterone in men. [http://www.livescience.com/6403-obesity-linked-testosterone-men.html. 20/3/2012].

7. Finn c. The forgotten symptoms of low testosterone levels. [http://www.thefactsaboutfitness.com $/ \mathrm{research} / \mathrm{test} . \mathrm{html}$. 20/3/2012].

[8]. Swerdkiff RS, Wang C, Bhasin S. Developments in the control of testicular function. Bailieres Clin Endocrinol Metab 1992; 6:451483 .

[9]. Sandeep D, Sathyavani P, Manak S, Arindam B, Ajay C, Paresh D. Frequent Occurrence of Hypogonadotropic Hypogonadism in Type 2 Diabetes. Clin Endoc and Metab 2004; 89: 5462-8.

[10]. Ballister J, Carmen Munoz M, Dominguez J, Rigau T, Guinovart J, Rodriguez-Gil J. Insulin-Dependent Diabetes Affects Testicular Function by FSH- and LH-Linked Mechanisms. J. Androl 2004;25:705-719.

[11]. Feng H1, Jay PD, Sandlow JI, Sparks AET, Sandra A, Zheng LJ. Decreased expression of the c-kit receptor is associated with increased apoptosis in subfertile human testes. Fertile Steril. 1999;71:85-89.

[12]. Hurtado de Catalfo G, Nelva I, De Gomez Dumm T. Lipid dismetabolism in Leydig and Sertoli cells isolated from streptozotocindiabetic rats. Int J Biochem Cell Biol. 1998;30:1001-1010.

[13]. Romanelli F, Valenca M, Conte D, Isidori A, Negro-villar A. Arachidonic acid and its metabolites: effects on testosterone production by rat Leydig cells. J Endocrinol Invest. 1995;18:186-193.

[14]. Riddle O, Bates RW, Dykshorn SW. The preparation, identification and assay of prolactin- a hormone of the anterior pituitary. Am $J$ Physiol. 1933;105:191-216.

[15]. Freeman ME, Kanyicska B, Lerant A, Nagy G. Prolactin: structure, function, and regulation of secretion. Physiol Rev 2000;80:1523-1631.

[16]. Mooradian AD, Morley JE, Billington CJ, Slag MF, Elson MK, Shafer RB. Hyperprolactinaemia in male diabetics. Postgrad Med J 1985;61:11-14.

[17]. Huang C, Snider F, Cross JC. Prolactin receptor is required for normal glucose homeostaiss and modulation of beta-cell mass during pregnancy. Endocrinology 2009;150:1618-1626.

[18]. Ben-Jonathan N, Hugo ER, Brandebourg TD, LaPensee CR. Focus on prolactin as metabolic hormone. Trends Endocrinol Metab 2006;17:110-116.

[19]. Mayfield J. Diagnosis and classification of Diabetes Mellitus:New Criteria. Am Fam Physician 1998; 58:1355-1362.

[20]. Trinder P. Determination of blood glucose using an oxidase-peroxidase system with a non-carcinogenic chromogen. $J$ Clin Pathol 1969;22:158-61.

[21]. Michael LB, Edward PF, Larry ES. Clinical Chemistry: Principle, Procedures, Correlations. $5^{\text {th }} \quad$ edition. $^{\text {Philadelphia: }}$ Lippincott Williams and Wilkins; 2005. p. 153-6.

[22]. Cohen P. The hypogonadal-obesity cycle. Medical Hypotheses 1999;52:49-51.

[23]. Kapoor D, Goodwin E, Channer KS, Jones TH. Testosterone replacement therapy improves insulin resistance, glycaemiccontrol, visceral adiposity and hypercholesterolaemia in Hypogonadal men with type II diabetes. Europ J Endocrinol 2006;154: 899-02.

[24]. Dandona P, Dhindsa S, Chandel A, Topiwala S. Low testosterone in men with type 2 diabetes- a growing public health concern. Diabetes Voice 2009;54:27-29.

[25]. Natah TM, Wtwt MA, Al-Saadi HK, Al-Saadi AH, Farhood HF. Study the levels of adiponectin, FSH, LH and sex hormones in Type 2 diabetes (NIDDM). JBAH 2013;3:172-81.

[26]. Ali ST, Shaikh RN, Ashfaqsiddiqi N, et al. Serum and urinary levels of pituitary-gonadal hormones in insulin-dependent and noninsulin dependent diabetic males with or without neuropathy. Arch Androl 1993;30:117-23.

[27]. Ando S, Rubens R, Rottiers R. Androgen plasma levels in male diabetics. Endocrinol Invest 1984;7:21-4

[28]. Hussein Z, Al-Qatsi J. Effect of diabetes mellitus Type 2 on Pituitary Gland Hormones (FSH, LH) in men and Women in Iraq. JNUS 2012;15:75-9.

[29]. Seethalakshmi L, Menon M, Diamond D. the effect of streptozotocin-induced diabetes on the neuroendocrine-male reproductive tract axis of the adult rat. $J$ Urol. 1987;138:190-194. 
Pattern of male sex hormones in type 2 diabetic patients in Nnewi, South Eastern Nigeria.

[30]. Saller CF, Chiodo LA. Glucose suppresses basal firing and haloperidol-induced increases in the firing rate of central dopaminergic neurons. Science 1980;210:1269.

[31]. Macleod RM. Regulation of prolactin secretion. In: Frontiers in Neuroendocrinology, In: Martini L. and Ganong WF editors. New York: Raven Press;1976. p. 169.

[32]. Kirby RW, Kotchen TA, Rees ED. Hyperprolactinemia - A review of recent clinical advances. Archives of Internal Medicine 1979;139:1419.

Table 1: Characteristics of the diabetic population according to the frequency of $E D(n=125)$

\begin{tabular}{|c|c|c|c|c|}
\hline \multirow[t]{2}{*}{ characteristics } & \multicolumn{3}{|c|}{ Frequency of ED (\%) } & \multirow{2}{*}{$\mathbf{P}$} \\
\hline & Often & Occasional & never & \\
\hline n & 55 & 49 & 21 & \\
\hline Age (years) & & & & 0.4 \\
\hline $30-40$ & $7(44)$ & $5(31)$ & $4(25)$ & \\
\hline 41-50 & 13(35) & $15(41)$ & $9(24)$ & \\
\hline $51-60$ & 28(46) & $26(43)$ & $7(12)$ & \\
\hline 61-70 & $7(64)$ & $3(27)$ & 1(9) & \\
\hline BMI $\left(\mathrm{Kg} / \mathrm{M}^{2}\right)$ & & & & 0.002 \\
\hline Normal & 21(33) & 32(50) & 11(17) & \\
\hline Overweight & 22(46) & 16(33) & $10(21)$ & \\
\hline Obesity & 12(92) & 1(8) & $0(0)$ & \\
\hline Duration of DM (years) & & & & 0.7 \\
\hline$<6$ & 27(46) & $22(37)$ & $10(17)$ & \\
\hline 6-10 & 10(35) & $15(52)$ & $4(14)$ & \\
\hline 11-15 & $10(42)$ & $9(38)$ & $5(21)$ & \\
\hline$>15$ & $8(62)$ & 3(23) & $2(15)$ & \\
\hline Diabetes Treatment & & & & 0.03 \\
\hline Oral alone & $45(50)$ & $32(35)$ & 14(15) & \\
\hline Insulin & $6(40)$ & $4(27)$ & $5(33)$ & \\
\hline Insulin + & $4(21)$ & $13(68)$ & $2(11)$ & \\
\hline Complication & & & & 0.001 \\
\hline $\begin{array}{llll}\text { Complication } & \text { Presence of } & \text { any }\end{array}$ & $52(51.5)$ & 41(40.6) & $8(7.9)$ & \\
\hline No complication & $3(12.5)$ & $8(33.3)$ & $13(54.2)$ & \\
\hline
\end{tabular}

Table 2: The mean levels of Age, Duration of Diabetes, Male sex hormones (FSH, LH, Testosterone and Prolactin), fasting plasma glucose (FPG) and body mass index (BMI) in type 2 diabetic subjects and in non-diabetic controls (Mean $\pm \mathrm{SD})$.

\begin{tabular}{cccc}
\hline Parameters & Subjects & Controls & P value \\
& $\mathrm{N}=125$ & $\mathrm{~N}=50$ & \\
\hline Duration of DM (years) & $7.7 \pm 5.7$ & & \\
Age (years) & $51.6 \pm 8.6$ & $49.18 \pm 11.46$ & $>0.05$ \\
Testosterone $(\mathrm{ng} / \mathrm{ml})$ & $3.9 \pm 1.9$ & $5.1 \pm 1.7$ & 0.001 \\
FSH $(\mu \mathrm{IU} / \mathrm{ml})$ & $6.3 \pm 3.8$ & $4.8 \pm 1.8$ & 0.007 \\
LH $(\mu \mathrm{IU} / \mathrm{ml})$ & $4.1 \pm 4.0$ & $2.9 \pm 1.6$ & 0.06 \\
Prolactin $(\mathrm{ng} / \mathrm{ml})$ & $21.0 \pm 6.1$ & $17.7 \pm 4.5$ & 0.001 \\
FPG $(\mathrm{mmol} /)$ & $7.9 \pm 3.7$ & $4.6 \pm 0.4$ & 0.001 \\
BMI $\left(\mathrm{kg} / \mathrm{m}^{2}\right)$ & $25.5 \pm 2.5$ & $25.1 \pm 1.6$ & $>0.05$ \\
\hline
\end{tabular}

Table 3: Correlation DDM with male sex hormones (FSH, LH, Testosterone and Prolactin) in type 2 diabetic subjects.

\begin{tabular}{lccc}
\hline & N & r & P-value \\
Parameters & & -0.006 & 0.943 \\
DDM VS. LH & 125 & -0.067 & 0.456 \\
DDM VS. FSH & 125 & 0.041 & 0.654 \\
DDM VS. TESTOSTERONE & & 0.143 & 0.113 \\
DDM VS. PROLACTIN & 125 & 125 & \\
\hline
\end{tabular}


Pattern of male sex hormones in type 2 diabetic patients in Nnewi, South Eastern Nigeria.

Table 4: Male sex hormones (FSH, LH, Prolactin and Testosterone), BMI, and FPG within age groups (30-40, 41-50, 51-60, and 61-70) in male DM2 subjects.

\begin{tabular}{|c|c|c|c|c|c|c|}
\hline Parameters & $30-40$ & $41-50$ & $51-60$ & $61-70$ & F-value & $\mathrm{P}$-value \\
\hline $\mathrm{N}$ & 16 & 37 & 61 & 11 & & \\
\hline $\operatorname{BMI}\left(\mathrm{kg} / \mathrm{m}^{2}\right)$ & $25.8 \pm 2.7$ & $25.1 \pm 2.1$ & $25.0 \pm 2.6$ & $24.8 \pm 2.8$ & 0.523 & 0.667 \\
\hline $\mathrm{FPS}(\mathrm{mmol} / \mathrm{l})$ & $8.0 \pm 4.4$ & $7.5 \pm 3.5$ & $7.9 \pm 3.8$ & $9.2 \pm 33.6$ & 0.546 & 0.652 \\
\hline Testosterone(ng/ml) & $4.1 \pm 1.9$ & $4.2 \pm 1.9$ & $3.8 \pm 1.9$ & $2.8 \pm 2.2$ & 1.599 & 0.193 \\
\hline Prolactin(ng/ml) & $21.8 \pm 7.0$ & $21.3 \pm 7.2$ & $20.8 \pm 5.4$ & $19.5 \pm 4.7$ & 0.353 & 0.787 \\
\hline $\mathrm{LH}(\mu \mathrm{IU} / \mathrm{ml})$ & $4.0 \pm 3.4$ & $3.7 \pm 3.5$ & $4.5 \pm 4.1$ & $3.5 \pm 3.1$ & 0.375 & 0.771 \\
\hline FSH $(\mu \mathrm{IU} / \mathrm{ml})$ & $6.5 \pm 4.5$ & $6.1 \pm 4.3$ & $6.6 \pm 3.3$ & $5.7 \pm 3.7$ & 0.252 & 0.860 \\
\hline
\end{tabular}

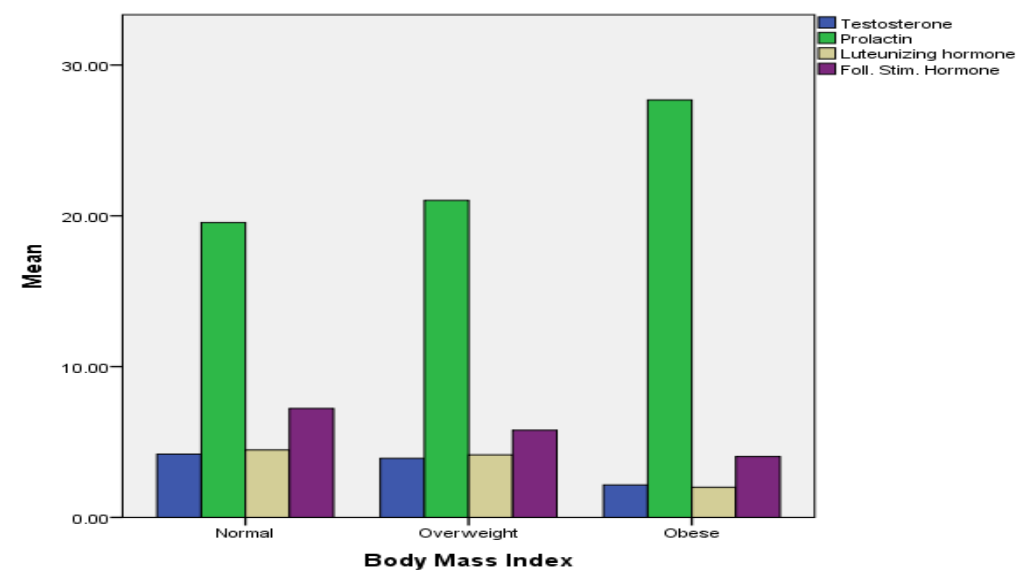

Figure 1: comparison of BMI categories with male sex hormones. 